\title{
CIDADANIA NO DISCURSO DAS DIRETRIZES CURRICULARES DO CURSO DE CIÊNCIAS CONTÁBEIS
}

\section{ARTIGO ORIGINAL}

BOMBARDELLI, Joel ${ }^{1}$

MATOS, Gleimiria Batista da Costa ${ }^{2}$

ARENAS, Marlene Valério dos Santos ${ }^{3}$

BRAGA, lluska Lobo ${ }^{4}$

ALMEIDA, Vanessa Fernanda Rios de ${ }^{5}$

BOMBARDELLI, Joel. Et al. Cidadania no discurso das Diretrizes Curriculares do curso de Ciências Contábeis. Revista Científica Multidisciplinar Núcleo do Conhecimento. Ano 05, Ed. 06, Vol. 04, pp. 36-50. Junho de 2020. ISSN: 2448-0959, Link de acesso: https://www.nucleodoconhecimento.com.br/contabilidade/cidadaniano-discurso

\section{RESUMO}

A cidadania funciona como uma prática discursiva, quando inscrita no modelo do capitalismo neoliberal contemporâneo de educação produz efeito de sentidos na simetria da trilogia de educação/trabalho/cidadania, interpelando o sujeito contador. A cidadania das ciências contábeis desliza para uma cidadania empresarial ou

1 Doutorado em Ciências da Linguagem (UNIVÁS). Mestre em Engenharia da Produção (UFSC). Graduado em Ciências Contábeis (UNIR).

2 Doutora em Desenvolvimento Regional.

${ }^{3}$ Doutora em Administração pela UFRS.

${ }^{4}$ Doutora em Administração pela UNIGRANRIO.

${ }^{5}$ Mestre em Administração. 
corporativa que se (re)produz um discurso político e social homogêneo e hegemônico. Dessa forma, levanta-se a questão: Nas Diretrizes Curriculares para o Curso de Graduação em Ciências Contábeis (DCCC) que orientam as propostas pedagógicas dos Cursos de Ciências Contábeis no Brasil está presente a questão da cidadania na educação/trabalho? Como funciona a discursividade da cidadania? O objetivo é analisar o funcionamento discursivo da questão da cidadania apresentada nas DCCC que orientam as propostas pedagógicas dos Cursos de Ciências Contábeis no Brasil. A metodologia está apoiada na perspectiva teórico-metodológica da Análise de Discurso de filiação a Pêcheux e Eni Orlandi, pode ser caracterizada quanto aos objetivos como explicativa, com delineamento de pesquisa documental baseado nas DCCC e tratamento e análise dos dados qualitativo. Os resultados desta análise demonstram que o profissional da contabilidade vive um conflito em ser cidadão e ser profissional conforme as DCCC. O enunciado "cidadania", faz parte de uma constelação de enunciados: produzido por discursos de governos e discursos empresariais, esse enunciado se torna edificante, funcionando como se fosse dignidade, orgulho, sucesso ou mesmo capacitação.

Palavras-chave: Ciências Contábeis, análise de discurso, cidadania.

\section{INTRODUÇÃO}

Neste trabalho, propõem-se analisar efeitos de sentido decorrentes do funcionamento da cidadania no discurso da capacitação formulada nas Diretrizes Curriculares Nacionais para o Curso de Graduação em Ciências Contábeis (DCCC), bacharelado, emitida pela Câmara de Educação Superior do Conselho Nacional de Educação, conforme Resolução CNE/CES 10 de 16 de dezembro de 2004.

Essas DCCC foram implantadas propondo projetos pedagógicos elaborados a partir de premissas políticas e sociais neoliberais, já socialmente consolidadas que sustentam um discurso de capacitação pelas competências e habilidades, como forma de ligar sociedade e conhecimento, por um lado, e, por outro lado, de silenciar outras discursividades que trabalham a "formação", esta apontada por Orlandi (2014) como mais robusta e indiciadora de outra estrutura política e de outra formação social. 
Rocha (2017) afirma que as políticas neoliberais começaram a se tornar hegemônicas internacionalmente entre as décadas de 1980 e 1990, e no Brasil consequentemente, época quando as instituições, organizações empresariais, fundações e governos desenvolveram e disseminaram um discurso do pró-mercado. Compreende-se que esse discurso de fomentação do neoliberalismo foi consciente e/ou inconscientemente realizado e produzindo efeito de sentidos na sociedade, como única solução possível e imaginária para os problemas econômicos e sociais dos indivíduos. Um conjunto de intelectuais, militantes e empresários previamente engajados, também financiavam essas ações de difusão do modo neoliberal social, principalmente no espaço acadêmico influenciando as futuras gerações.

Os professores e estudantes universitários eram beneficiados pela disponibilização de livros liberais para venda ou consulta, seminários, bolsas e programas de intercâmbio financiados por organizações e universidades estrangeiras, e concursos e monografias. E, finalmente, os empresários poderiam ter acesso à participação em uma rede de contatos com empresários importantes do país fomentadas não apenas pelos Institutos Liberais, mas também pelo IEE, cujo foco era justamente a formações de jovens empresários na doutrina liberal (ROCHA, 2017, p. 5).

Antes do discurso neoliberal, vale lembrar que o estudo superior em Ciências Contábeis no Brasil, o qual, desde a Monarquia até meados do século XX, era representado como objeto de domínio da burguesia, transformando-se, na contemporaneidade, em um produto de mercado destinado a um público massificado, objeto de consumo de outras classes sociais. Portanto, mantendo a assimetria das classes sociais.

O mercado de trabalho e as instituições que aparelham o Estado questionam a qualidade da formação dos futuros contadores, ou melhor, a capacitação desses profissionais para o mercado, contudo alimentam esse próprio sistema. Esse questionamento é fundado por um discurso empresarial e midiático que circula e dissemina um sentido de responsabilização e culpabilidade do sujeito incapacitado 
para o trabalho e consequentemente transforma a educação contínua em uma mercadoria.

Compreende-se o futuro contador em relação à questão da capacitação na proposta das DCCC, como um sujeito "moderno", livre e submisso ao mesmo tempo. A capacitação profissional do contador visa à construção de um sintoma de liberdade individual, que pode se manifestar pela sua motivação, liderança e pela sua livre iniciativa empresarial de empreender como decorrente do exercício de sua vontade. Concomitantemente, ele se submete profissionalmente às questões exclusivas do mercado ao se posicionar em busca das competências e habilidades descritas nas diretrizes, inscrevendo-se na condição social capitalista neoliberal, na qual, entretanto, ele já se encontra, no modo de existência, como descrito por Deleuze (1992) em que os anéis da serpente são ainda mais complexos.

As evidências da capacitação e profissionalização parecem ser constitutivas das políticas públicas de ensino, em especial, do ensino superior no Brasil. A questão do perfil profissional se enuncia no ensino superior brasileiro desde sua instituição, no ano de 1808, com a vinda da família Real Portuguesa, ocasião em que houve a criação de curso superior na área da saúde. E, assim, nos anos seguintes, com a fundação dos cursos de Engenharia, Agricultura, Pintura e Escultura, e Direito (SAMPAIO, 1991). Para Sampaio (1991) e Cunha (2007), nesses cursos prevalecia o cunho de especializações técnicas, o que contribuía, de um lado, para a produção de burocratas para o Estado, e, de outro lado, de profissionais liberais para o mercado. A contabilidade embora ciência se enquadra nessas questões de técnica e liberais de mercado.

Dessa maneira, seria possível considerar outra redação para a Resolução CNE/CES no 10 de 2004, tomada aqui como um instrumental de subjetivação, e que pudesse significar a noção de formação social. Esta noção, para Orlandi (2014), difere de formação de sociedade, em outra formação discursiva, pois, na formação social estas posições-sujeito se constituem em um movimento contínuo de processos de identificação, com conhecimento e saberes A formulação dos enunciados das DCCC 
foi alicerçada na capacitação de competências e habilidades conforme os artigos $3^{\circ} \mathrm{e}$ 4ํㅡ, assim descritos:

Artigo 3으 O Curso de graduação em Ciências Contábeis deve ensejar condições para que o futuro contador seja capacitado a [...]

Artigo 4ㅇ O curso de graduação em Ciências Contábeis deve possibilitar formação profissional que revele, pelo menos, as seguintes competências e habilidades [...]" (BRASIL, 2004, grifos nossos).

Propondo novos enunciados, esses na concepção de formação de Orlandi (2014) como alicerce de conhecimento, poderiam produzir outros efeitos de sentido para a educação contábil, com sujeitos contadores ocupando outros lugares na formação social. Nessa propositura se propõe formular metaforicamente uma nova redação para os artigos $3^{\circ}$ e $4^{\circ}$ :

Artigo 3으 $\mathrm{O}$ curso de graduação em Ciências Contábeis deve ensejar condições para que o futuro contador seja formado para[...]; e,

Artigo 4으 curso de graduação em Ciências Contábeis deve possibilitar formação profissional que revele, pelo menos, os seguintes conhecimentos/saberes/experiências[...].

Para a nova ordem econômica a educação é uma questão de desenvolvimento econômico, de acesso ao trabalho pela forma de capacitação, como um treinamento amestrador, o indivíduo, pelo imaginário social, filia-se à fórmula lógico-racional de capacitar-se, segundo a qual deve-se estudar para o trabalho. E, consequentemente, essa lógica se funda como se fosse a única regra capaz de fazer emergir o indivíduo social e economicamente, e, em decorrência, constituí-lo de seus plenos direitos.

Esses direitos enquadram o direito ao consumo e à cidadania. Para Orlandi (2014) há uma conjugação entre consumo e cidadania, pois, os trabalhadores qualificados ocupando ao mesmo tempo a posição de consumidores e cidadãos, alimentam o 
processo do mercado de trabalho qualificado. Como os trabalhadores qualificados são significados também como cidadãos.

Pergunta-se: Nas Diretrizes Curriculares para o Curso de Graduação em Ciências Contábeis, que orientam as propostas pedagógicas dos Cursos de Ciências Contábeis no Brasil está presente a questão da cidadania na educação/trabalho? Como funciona a discursividade da cidadania?

Essas questões, serão tratadas no processo de análise discursiva, com o suporte teórico da Análise de Discurso francesa de Pêcheux e Orlandi que articula o linguístico com o social (constitutivo do discurso) e o histórico.

Este artigo buscou-se compreender o funcionamento de uma prática discursiva, inscrita no modelo do capitalismo neoliberal contemporâneo de educação produz efeito de sentidos na simetria da trilogia de educação/trabalho/cidadania. Além dessa introdução o artigo está estruturado considerando a discursividade da cidadania e seu efeito de sentidos possíveis entre locutores e o discurso uma prática social.

\section{DESENVOLVIMENTO}

A discursividade das proposições das DCCC não poderia ser indiferente quanto a não colocar a questão da cidadania em relação à da contabilidade, pois, ela funciona pela memória do ordenamento jurídico da educação. As capacitações descritas nas DCCC se edificam pela interpelação ideológica do sujeito capitalista contemporâneo (futuro contador), o sujeito do direito e dever, que se filia - pela lógica estabilizada da contabilidade e pela busca de uma metalinguagem que pudesse transmitir uma verdade - a determinadas redes de sentido na/da memória discursiva.

O enunciado "cidadania" (sozinho ou em uma sequência sintática) imerge para uma rede de relações implícitas - heterogêneas que funcionam sob diferentes registros discursivos, com estabilidade lógica variável, e que ainda, como coloca Pêcheux (2006), sobre o funcionamento do enunciado é profundamente opaco. Como uma discursividade política, e de performance capitalista, a cidadania, brasileira ou das 
DCCC pode funcionar em similaridade com o enunciado "On a gagné" "[Ganhamos"] pronunciado pelos franceses em comemoração à vitória de François Mitterrand em 1981. Pois, "ganhamos" e "cidadania" tomada como objeto discursivo, imerge em alusões para "explicitar e descrever montagens, arranjos sócio-históricos de constelação de enunciados" (PÊCHEUX, 2006, p. 60). O enunciado "cidadania", seguindo raciocínio de Orlandi (2012, p. 123), faz parte de uma constelação de enunciados: produzido por discursos de governos e discursos empresariais, esse enunciado se torna edificante, funcionando como se fosse dignidade, orgulho, sucesso ou mesmo capacitação.

Assim, a Resolução CNE/CES 10/2004 em seu inciso VI do artigo 4ำ dispõe a formulação das competências e habilidades contábeis relaciona o contador a uma forma segundo a qual ele deve exercer com responsabilidade as funções contábeis, designado, pelas informações contábeis por ele produzidas aos outros (agentes econômicos e administradores), a construção de valores orientados para a cidadania, como se as informações contábeis já fossem por si só portadoras de cidadania.

Compreende-se que o instrumento das DCCC coloca a questão da cidadania como um assessório da informação contábil, mas, esse entendimento pode estar atrelado a uma discursividade contábil uníssona que faz deslizar a informação contábil para o controle social, da transparência, da prestação de contas e fiscalização dos recursos (em especial os recursos públicos), e, por conseguinte, da cidadania. Ou seja, o sentido de cidadania é determinado pelas performances organizacionais, sendo (res)significado por educação, trabalho e consumo. Paradoxalmente, o contador, pela "mínima" capacitação, apropria-se da trilogia educação/trabalho/consumo que o torna cidadão.

O futuro contador se capacita, termina o curso e torna-se cidadão; e aí sim como cidadão poderá construir valores para a cidadania. A capacitação para o futuro contador responsável e cidadão está apresentada nas DCCC, no inciso VI do artigo 4 ํ da Resolução CNE/CES 10/2004: 
VI - exercer suas responsabilidades com o expressivo domínio das funções contábeis, incluído noções de atividades atuariais e de quantificações de informações financeiras, patrimoniais e governamentais, que viabilizem os agentes econômicos e aos administradores de qualquer segmento produtivo ou institucional o pleno cumprimento de seus encargos quanto ao gerenciamento, aos controles e à prestação de contas de sua gestão perante à sociedade, gerando também informações para a tomada de decisão, organização de atitudes e construção de valores orientados para a cidadania. (BRASIL, 2004, grifo nosso)

A organização do enunciado "construção de valores orientados para a cidadania", parece funcionar produzindo o efeito de que toda a produção da atividade do contador estaria direcionada ou tivesse como finalidade a cidadania (sua produção, sua promoção, sua garantia etc.). Pela sua responsabilidade de exercer a função contábil, o contador teria que organizar atitudes e construir valores orientados para a cidadania, para os usuários das informações contábeis. As noções de contabilidade e atuaria levariam à produção de informações íntegras, o que permitiria serem utilizadas pelos agentes econômicos e sociais, de modo que estes pudessem tomar decisões também coerentemente orientadas pelos valores de cidadania. O contador, nessa perspectiva, tem responsabilidade e compromisso com a/para cidadania.

Destaca-se que, nesse espaço discursivo das ciências contábeis, pode-se considerar a cidadania discursivamente constituída por uma língua de madeira, que nos tempos do capitalismo neoliberal contemporâneo, restringe a ressonância de sua significação, dispersando-a ao/com o vento. Esta dispersão funciona no discurso de entidades, governos e instituições de educação: as DCCC, embora pareçam ser meramente informações técnicas, são rápidas em disseminar os conceitos da dominação capitalista neoliberal, sob um enredo de mudança, de necessidade para a "adequação" da sociedade aos tempos de modernidade.

$\mathrm{Na}$ historicidade brasileira, a relação entre a constituição da nossa língua e sua articulação na discursividade da cidadania, conforme Orlandi (2013), se concebe não 
relativamente ao direito jurídico-político, mas pela crença na possibilidade de transformação pela via da educação, travestida na forma da capacitação profissional, do treinamento, ao qual o sujeito social brasileiro deve se submeter. No Brasil, independente há quase dois séculos, sendo um século funcionando como república, Orlandi $(2013$, p. 257) ressalta:

[...] não se nasce cidadão. Não se trata assim de uma questão jurídicopolítica. As leis são uma projeção de um desejo. Essa tarefa - de transformação e não de direito: "virar cidadão" - fica para a educação, ou seja, é uma questão pedagógica que pode ou não atingir o sujeito social brasileiro. (ORLANDI, 2013, p. 257)

Nessa concepção de Orlandi (2013), temos o Estado e neoliberalismo funcionando na educação e significando a cidadania. De modo que a educação diga quem (não) é cidadão, ou seja, qual sujeito que pode ser cidadão na sociedade brasileira. A escola pela educação transforma o sujeito em cidadão, distinguindo-o daquele para quem a cidadania não significa (da mesma forma). Tem-se então, a capacitação do futuro profissional pelo curso superior em ciências contábeis: um contador que deve "formarse", capacitar-se, também, necessariamente, como um cidadão que zela por outro pelas informações, e apagando o conhecimento, informação não é o mesmo que o "conhecimento".

A cidadania das DCCC também nos remete à memória discursiva, pela "língua de madeira", dos dizeres disponibilizados nas leis da educação, (re)produzidos em outros documentos anteriores, como a Constituição Brasileira de 1988 e a Lei de Diretrizes e Base da Educação de 1996, textualidades que articulam a significação da cidadania nas DCCC.

A Constituição Federal de 1988 funciona (res)significando as constituições anteriores, apresenta como um dos princípios fundamentais do Estado Democrático de Direito, a "cidadania", o termo está escrito solto, uno, sem complemento, conforme artigo $1^{\circ}$ : "[...] constitui-se em Estado Democrático de Direito e tem como fundamentos: I - a 
soberania; II - a cidadania; III - a dignidade da pessoa humana; IV - os valores sociais do trabalho e da livre iniciativa; V - o pluralismo político" (grifo nosso).

Ainda no texto da Constituição de 1988, a cidadania é apresentada no Capítulo da Educação da Cultura e do Desporto, em que se formula a articulação entre educação e qualificação para o trabalho: nesta relação forja-se uma trilogia, qual seja, educação/trabalho/cidadania. A transcrição do artigo 205 da Constituição Federal de 1988(17) reproduz um enunciado com essa trilogia: "a educação, direito de todos e dever do Estado e da família, será promovida e incentivada com a colaboração da sociedade, visando ao pleno desenvolvimento da pessoa, seu preparo para o exercício da cidadania e sua qualificação para o trabalho" (grifos nossos).

Essa trilogia educação/trabalho/cidadania, em continuidade, se organiza e toma forma pela Lei das Diretrizes e Base da Educação de 1996, que apresenta a cidadania no texto descrito como princípios e fins da educação nacional, relacionado à educação como um preparo para o exercício da cidadania. Assim, encontramos no art. $2^{\circ}$ : "a educação, dever da família e do Estado, inspirada nos princípios de liberdade e nos ideais de solidariedade humana, tem por finalidade o pleno desenvolvimento do educando, seu preparo para o exercício da cidadania e sua qualificação para o trabalho".

O processo discursivo que significa os textos da Constituição Brasileira e da Lei de Diretrizes e Base da Educação instaura as condições simbólicas que sustentam o caráter político-jurídico-administrativo das DCCC para o Curso de Graduação em Ciências Contábeis, em que a "cidadania" é formulada como um objeto de valores a ser construído e/ou inserido pela informação gerada pela contabilidade, ou seja, a cidadania como se estivesse inclusa, inserida na informação contábil produzida pelos contadores para que terceiros, os usuários das informações, na tomada de decisões revelassem a cidadania. Uma cidadania pela informação. Uma informação contábil sem cidadania significa decisão sem cidadania.

A concepção do discurso político-administrativo da nossa legislação de educação, amparada pelo apoio coercitivo do jurídico sobre os sujeitos, mesmo que o jurídico 
queira assegurar direitos individuais ou coletivos, estabelece que o sentido de cidadania é estabilizado nos efeitos de evidência de educação e de trabalho. E o trabalho desliza como simetricamente para a produção de riqueza.

E, pela trilogia educação/trabalho/cidadania funciona o imaginário das condições de existência do sujeito e da sociedade. O sujeito educado é um trabalhador capacitado, livre, empreendedor, empreendedor de si mesmo. Contudo, cidadão educado trabalhando não significa cidadania. As políticas públicas de educação funcionam dividindo o social, acirrando as assimetrias e desigualdades, produzindo certo deslizamento que associa educação à discriminação. O não cidadão já se encontra discriminado, ele é um sujeito sem a capacidade das habilidades e competências capaz de "produzir valores" para a cidadania, pois, o trabalhador, empreendedor é sempre reconhecido pela falta de capacitação.

A escola, a universidade, o sistema educacional como um todo, são espaços sociais classificadores, separadores, como um processo de triagem que produzem uma divisão social entre o sujeito capacitado e o incapacitado (ORLANDI, 2016), quem tem conhecimento e quem não tem, aprovados e os reprovados.

Tem-se uma cidadania que significa deslizando-se para efeitos de sentido como emprego, trabalho e renda. Uma educação capacitadora e não formadora. E, no caso das ciências contábeis, a ciência patrimônio, da riqueza, do lucro etc. Esses termos também funcionam em uma deriva para a cidadania. O sujeito com patrimônio, riqueza, renda etc. originado pelo lucro, renda ou pelo trabalho é um cidadão completo.

O discurso da educação para a cidadania é formulado e funciona como uma língua de vento: a educação mira quase que exclusivamente o trabalho/renda/lucro, e da combinação educação e trabalho surge o sujeito "travestido" de cidadão. A cidadania contábil desliza para a cidadania empresarial, cidadania corporativa. 


\section{O FUNCIONAMENTO DO DISCURSO DA/PELA CIDADANIA DAS DIRETRIZES CURRICULARES NACIONAIS PARA O CURSO DE GRADUAÇÃO EM CIÊNCIAS CONTÁBEIS}

A discursividade das DCCC se concretiza nos relatórios elaborados pelos profissionais da contabilidade. Como primeiro exemplo, pode-se mencionar o caso da Empresa Natura, indústria de cosméticos que utiliza como uma das suas matériasprimas as essências florestais da Amazônia.

Em seu Relatório Anual[6] do ano de 2004, destaca uma reportagem de premiação obtida pela Natura, referente ao "Guia de Boa Cidadania Corporativa", sob o título de "Como compartilhar valores - A estratégia da Natura é convencer seus parceiros a apostar na responsabilidade social".

A estratégia junto a seus fornecedores de matéria-prima do Estado do Amapá, que são os produtores (povos ribeirinhos, seringueiros, produtores de castanha e índios), visando à sustentabilidade do negócio, consiste em fazer parceria com o Ministério da Educação para incentivar o retorno à sala de aula dos produtores. Essa solução teria motivado as vendedoras (consultoras) da Natura a serem mais dedicadas nas vendas dos produtos da empresa, por ser uma solução ligada a "causas sociais", fazendo crer que as consultoras queriam, inclusive, participar ativa e diretamente do referido projeto empresarial.

Tantos os produtores quanto às consultoras da Natura, e os contadores que elaboram os relatórios, são interpelados pelo capitalismo neoliberal. Nesse sentido, Orlandi e Lagazzi-Rodrigues (2015, p. 23-24) afirmam:

o sujeito moderno e ao mesmo tempo livre e submisso, determinado pela exterioridade e determinador do que diz: essa é a condição de sua responsabilidade (sujeito jurídico, sujeito a direitos e deveres) e de sua coerência (não contradição) que lhe garantem, em conjunto, sua impressão de unidade e controle de sua vontade, não só dos outros, mas 
até de si mesmo, bastando para isso ter poder e consciência. Essa é ilusão.

O discurso empresarial e contábil é um discurso homogêneo e hegemônico, que opera a substituição do "lucro" por outros temos, palavras mais sociais, inclusive menos capitalistas, enquanto evidência do funcionamento do capitalismo neoliberal, pela visibilidade supostamente positiva de um certo tipo de cidadania.

Um desses discursos formula as "causas sociais" das empresas privadas, que inclusive produzem estratégias midiáticas para demonstrar para a sociedade o compromisso das empresas com tais causas, como se as empresas fossem participes ou articuladoras/executoras de políticas públicas, todavia, nada mais são que um comportamento ardil com seus consumidores e colaboradores, cujo único objetivo é ampliar seu mercado consumidor e o lucro.

No mercado financeiro, temos o caso da peça contábil do Relatório de Administração do Balanço Patrimonial Consolidado do Banco Itaú[7], do ano de 2015, também elaborado por contadores/gestores: apresenta a Fundação Itaú Social como promotora das ações do banco em educação e saúde. A Fundação tem como foco o desenvolvimento, a implantação e disseminação de tecnologias sociais que visam ao progresso das políticas públicas de educação, para potencializar o engajamento de seus colaboradores. Contudo essas políticas públicas são focadas na capacitação e não na formação das gerações futuras.

A formação crítica é excluída no processo de capacitação. Esses balanços, textos que Fairclough (2001) entende serem do tipo informação-e-publicidade ou falar-evender, como o Balanço Socioambiental, os Relatórios de Gestão, as Demonstrações Contábeis, tornaram-se usuais em várias ordens de discursos institucionais na sociedade contemporânea. Combinam as informações financeiras regulamentadas à publicidade que visa à venda e o consumo e ainda se beneficiam de certos incentivos fiscais que reduzem os pagamentos de impostos ao Estado. 
Em outros termos, pode-se compreender como publicidade de entidades privadas financiadas com dinheiro público. Esses textos testemunham "um movimento colonizador da publicidade do domínio do mercado de bens de consumo, em um sentido estrito, para uma variedade de outros domínios" (FAIRCLOUGH, 2001, p. 151). A discursividade das DCCC toma forma nesses textos institucionais produzidos pelo contador capacitado no modelo neoliberal de educação superior.

Outro exemplo de articulação discursiva institucional é o apresentado nas Demonstrações Contábeis da JBS[8], no exercício 2012, que exibe o grupo empresarial como um dos maiores produtores de proteínas animal do mundo e com supostos compromissos com a responsabilidade social, por meio das atividades desenvolvidas pelo seu Instituto Germinare.

O objetivo do Instituto é educacional: propõe "oferecer gratuitamente ensino fundamental e médio de excelência, formando cidadãos bem preparados do ponto de vista acadêmico e humano, com repertório cultural amplo, valores éticos consolidados e atitudes positivas diante da vida e da sociedade". Contudo, os valores "éticos, humanos ou atitudes sócias positivas" parecem não ser o forte da organização, pois, a mesma participou ativamente de um cenário[9] de delações, investigações e de corrupção.

\section{CONSIDERAÇÕES FINAIS}

Como conclusão compreendemos que a relação das ciências contábeis com a cidadania constitui um espaço social significado, construído pelo discurso institucional que produz, como efeito, a comodificação da educação, ligando-a ao trabalho e ao consumo. Isto é, o contador, no exercício responsável de suas atribuições, produz informações contábeis referentes à performance e aos resultados das organizações, que podem produzir um efeito metafórico que se pode interpretar como: pela mínima capacitação da educação contábil.

O sujeito contador se torna minimamente um burguês ou um instrumento para (re)produzir o sistema capitalista neoliberal. Contribui para a concentração e 
centralização do capital, produzindo um discurso de cidadania já inserido no modelo capitalista/neoliberal articulado na trilogia educação/trabalho/cidadania.

As Diretrizes Curriculares Nacionais para o Curso de Graduação em Ciências Contábeis proporcionam para Análise do Discurso um espaço de linguagem e historicidade, em um discurso estatal-legal e empresarial, com um avatar científico, subordinado ao discurso político dominante, que condiciona o dizer e as condições de produção desse dizer sobre a cidadania e educação.

O discurso estatal-legal-empresarial mesmo querendo funcionar como um espaço discursivo lógico e estabilizado como uma ciência régia é falho e incompleto. A cidadania contábil como proposta nas DCCC produz um aumento das assimetrias entre as classes sociais, pois a cidadania corporativa existe pela condição da exploração espoliadora sobre o trabalhador, ou seja, as próprias corporações produzem desigualdades e depois em outro discurso dizem querer reparar o já (re)produziram.

O enunciado edificante da cidadania, filia-se a um discurso moralista, neoliberal, e aos ventos da contemporaneidade mundial, que se propagam na sociedade de modo dissimulado, como se fossem transparentes, sem opacidade. O sujeito torna-se contador pela capacitação, e, na sequência, em decorrência, torna-se cidadão, sendo dissimuladamente inscrito na memória do capitalista de uma cidadania corporativa desenhada pelo funcionamento do discurso jurídico-administrativo a serviço do modo de produzir do neoliberalismo.

No espaço das empresas, dos negócios, os sujeitos encontram uma situação de tomada de consciência mesmo que inconsciente do lugar que lhe é atribuído, da sua classe social. Desse modo, as palavras ganham sentido a partir das posições em que são empregadas, das formações discursivas nas quais as palavras adquirem seus sentidos possíveis. A cidadania corporativa, como linguagem dos negócios, funciona no imaginário social como forma de distribuição de lucros, contudo o seu funcionamento orgânico está em simetria com a geração de lucros. 
Todavia, há que se compreender a contabilidade como um processo de produção de sentidos, e a "linguagem contábil", por sua vez, funcionando também pelo prisma de que um sentido sempre desliza /deriva para outro sentido, sujeito e sentido se constituem ao mesmo tempo. Nessa direção, pode-se afirmar, por exemplo, que o sentido de cidadania tem efeito de sentido aberto, significando diferentemente, por um lado, para quem trabalha, por outro lado, para quem não tem trabalho.

A resistência dos sujeitos contadores cidadãos aos anéis da serpente deleuziana, pode emergir por uma concepção de educação, seja ela básica ou superior, mas, uma educação que não proporcione exclusivamente o trabalho, mas crie espaço para a crítica e para as mudanças e alterações sociais.

Deslocar a concepção de capacitação para uma concepção de formação do acadêmico de ciências contábeis, ou seja, privilegiar o conhecimento/saber pode proporcionar ao sujeito contador uma posição de discernir e/ou reconhecer uma prática de formação social diferente, o que Ihe instaura como possibilidade a inscrição em outra memória de cidadania que não a corporativa. O discurso da/pela cidadania não se fecha, não tem início e nem fim, mesmo no pragmatismo das ciências contábeis.

\section{REFERÊNCIAS}

BRASIL. Constituição da República Federativa do Brasil: promulgada em 5 de outubro de 1988. Brasília, DF: Senado Federal.. Disponível: https://www.planalto.gov.br/ccivil_03/constituicao/ConstituicaoCompilado.htm. Acesso em novembro/2019

BRASIL. Ministério da Educação. Conselho Nacional de Educação. Câmara de Educação Superior. Resolução CNE/CES 10, de 16 de dezembro de 2004.

BRASIL. Ministério da Educação. Lei de Diretrizes e Bases da Educação Nacional. Lei n. 9.394/96. Disponível em: http://www.planalto.gov.br/ccivil_03/Leis/L9394.htm. Acesso em novembro de 2019. 
CUNHA, Luiz Antônio. A universidade temporã: o ensino superior, da colônia à era Vargas. 3ª. ed. São Paulo: Editora UNESP, 2007.

DELEUZE, G. Post-scriptum sobre as sociedades de controles, L'autre Journal. n. 1, maio1990. [Trad. Bras. em Conversações, 1972-1990. Rio de Janeiro: Ed. 34, 1992]. Disponível

http://www.portalgens.com.br/filosofia/textos/sociedades_de_controle_deleuze.pdf. Acesso em novembro de 2016.]

FAIRCLOUGH, Norman. Discurso e mudança social. Trad. Bras. Brasília: Editora da Universidade de Brasília. 2001.

GADET, Françoise; PÊCHEUX, Michel. A língua inatingível. O discurso na história da língua. Trad. Bras. $2^{a}$ ed. Campinas: Ed. RG, 2010.

HERBERT, Thomas. Reflexões sobrea situação teórica das ciências sociais e, especialmente, psicologia social. Analise de Discurso: Michel Pêcheux. Textos escolhidos por: Eni Puccinelli Orlandi: análise de discurso. Campinas, SP: Pontes, 2016. p. $21-54$.

ORLANDI, Eni. Palestra proferida na Univás, no dia 25 de agosto de 2016

ORLANDI, Eni. Análise de Discurso: princípios e procedimentos. 12ª . ed. Campinas: Pontes, 2015.

ORLANDI, Eni. Discurso em análise: sujeito sentido e ideologia. 2ª ${ }^{a}$ ed. Campinas: Pontes, 2012.

ORLANDI, Eni. Formas de conhecimento, informação e políticas públicas. Revista Animus. Santa Maria, v. 9, n. 17, 2010. Disponível em https://periodicos.ufsm.br/animus/article/view/2373/2458. Acesso outubro de 2016.

ORLANDI, Eni. Língua e conhecimento linguístico: para uma história das ideias no Brasil. 2ª ed. São Paulo: Cortez, 2013. 
ORLANDI, Eni.. Formação ou capacitação? Duas formas de ligar sociedade e conhecimento. Em: FERREIRA, E.L.; ORLANDI, E.P. (Orgs.). Discursos sobre a inclusão. Niterói: Intertexto, 2014.

ORLANDI, Eni; LAGAZZI-RODRIGUES, Suzy (Orgs.). Introdução às ciências da linguagem: discurso e textualidade. Campinas: Pontes, 2015.

PÊCHEUX, M. Análise Automática do Discurso (AAD-69). Em: GADET, F.; HAK, T. (Orgs.) Por uma Análise Automática do Discurso: uma introdução à obra de Michel Pêcheux. Trad. Bras. Campinas: Unicamp, 1990.

PÊCHEUX, M. Análise de discurso - Michel Pêcheux [Textos escolhidos por Eni P. Orlandi]. Campinas: Pontes, 2011.

PÊCHEUX, M. L'étrange miroir de l'analyse de discours. In: Langages, 15e année, n62, 1981. Analyse du discours politique. pp. 5-8. Disponível em: https://www.persee.fr/doc/lgge_0458-726x_1981_num_15_62_1872. Acesso em abril/2020

PÊCHEUX, M. O discurso: estrutura ou acontecimento. Trad. Bras. $4^{a}$ ed. Campinas: Pontes, 2006.

RANCIÈRE, Jaques. A partilha do sensível: estética e política. Trad. Bras. São Paulo: Exo experimental org.; Ed. 34, 2005.

ROCHA, Camila. Passando o bastão: a nova geração de liberais brasileiros. Nuevo Mundo Mundos Nuevos [En ligne], Colloques, mis en ligne le 02 octobre 2017, $\begin{array}{lllll}\text { consulté } & \text { le } & 26 & \text { avril } & 2020 .\end{array}$ https://journals.openedition.org/nuevomundo/71327; DOI: https://doi.org/10.4000/nuevomundo.71327

SAMPAIO, Helena. Evolução do ensino superior brasileiro, 1808-1990. Documento de trabalho 8/91, Núcleo de Pesquisa sobre Ensino Superior Brasileiro da Universidade 
de São Paulo, 1991. Disponível em http://nupps.usp.br/downloads/docs/dt9108.pdf; acesso em out/2016.

\section{APÊNDICE - REFERÊNCIAS DE NOTA DE RODAPÉ}

6. O Relatório Anual da Natura (Empresa de cosméticos) de 2004 é o que costuma ser denominado de Balanço Socioambiental: tem o caráter informativo de apresentar ao conhecimento público detalhes das atividades e resultados econômico-financeiros da empresa, sendo elaborado segundo conceitos de transparência, abrangência e integridade, e em conformidade com organismos nacionais e internacionais. O Relatório Anual da Natura de 2004 está disponível em www.natu.infoinvest.com.br/ptb/1762/Port_Rel_Anual_2004.pdf; acesso em dezembro de 2016.

7. O Balanço Patrimonial Consolidado do Banco Itaú (exercício 2015) encontra-se disponível

em https;//www.itau.com.br/_arquivosestaticos/RI/.../IFRS31122015_port.pdf; acesso em dezembro de 2016.

8. As Demonstrações Contábeis do Exercício de 2012 do Grupo Empresarial JBS encontra-se disponível

em: www.jbss.infoinvest.com.br/enu/.../DF\%20311212_português_ completa_final.pdf. Acesso em dezembro 2016.

9. Os sócios majoritários do grupo empresarial JBS realizaram em junho de 2017 uma delação premiada sobre compra de privilégios empresariais junto a políticos e entidades públicas. Foram apresentados áudios/vídeos gravados com autoridades que indicam diálogos sobre pagamento de propina, carregamento de mala de dinheiro etc.

Enviado: Maio, 2020.

Aprovado: Junho, 2020. 